\title{
PENINGKATAN PENGETAHUAN KESEHATAN REPRODUKSI REMAJA PEMERIKSAAN PAYUDARA SENDIRI DENGAN METODE AUDIO VISUAL
}

\author{
Kartika Sari ${ }^{1}$, Rini Susanti ${ }^{2}$, Isri Nasifah ${ }^{3}$ \\ ${ }^{1}$ Prodi Kebidanan, Universitas Ngudi Waluyo, Semarang \\ ${ }^{2}$ Prodi Kebidanan, Universitas Ngudi Waluyo, Semarang \\ ${ }^{3}$ Prodi Kebidanan, Universitas Ngudi Waluyo, Semarang
}

\begin{abstract}
Abstrak
Kanker payudara merupakan salah satu prevalensi kanker tertinggi di Indonesia, yaitu 50 per 100.000 penduduk. Sementara itu, kanker payudara termasuk dalam 10 penyebab kematian terbanyak pada perempuan di Indonesia dengan angka kematian 21,5 per 100.000 penduduk. Riset Penyakit Tidak Menular (PTM) 2016 menyatakan perilaku masyarakat dalam deteksi dini kanker payudara masih rendah. Tercatat 53,7\% masyarakat tidak pernah melakukan SADARI, sementara 46,3\% pernah melakukan SADARI. Pencegahan yang tepat dan maksimal untuk penyakit tidak menular seperti kanker payudara adalah dengan dilakukannya promosi kesehatan dan deteksi dini antara lain berupa pencegahan primer, sekunder dan tertier. pencegahan yang paling mudah dan murah dilakukan adalah pencegahan primer yaitu dengan SADARI karena pemeriksaan SADARI dapat dilakukan oleh individu itu sendiri tanpa perlu ke petugas kesehatan. Pemberian informasi dengan media audio visual akan lebih praktis dan fleksibel bagi masyarakat dalam meningkatkan pengetahuan tentang pentingnya pemeriksaan SADARI. Sebab media tersebut merupakan sumber informasi yang dapat mempengaruhi tingkat pengetahuan. Jenis penelitian yang digunakan adalah pre eksperimental. Sampel penellitian ini adalah remaja putri di MA Darul Maarif. Metode yang akan dilakukan adalah ceramah, diskusi dan pemutaran video sadari. Hasil penelitian di MA Darul Maarif, sebagian besar siswi memiliki pengetahuan sedang sejumlah 25 siswi (54\%) saat pretest sedangkan pengetahuan saat posttest sebagian besar siswi memiliki pengetahuan tinggi sejumlah 33 siswi (72\%). Dan terdapat peningkatan pengetahuan di sekolah tersebut saat sebelum intervensi dan sesudah intervensi dengan media audio visual.
\end{abstract}

Kata kunci : pengetahuan, sadari

\section{IMPROVEMENT OF ADOLESCENT REPRODUCTIVE HEALTH KNOWLEDGE BREAST EXAMINATION USING AUDIO VISUAL METHOD}

\begin{abstract}
Breast cancer is one of the highest cancer prevalence in Indonesia, which is 50 per 100,000 population. Meanwhile, breast cancer is included in the top 10 causes of death in women in Indonesia with a mortality rate of 21.5 per 100,000 population. Non-Communicable Disease Research (PTM) 2016 states that community behavior in early detection of breast cancer is still low. It was recorded that $53.7 \%$ of the people had never done breast self-examination, while $46.3 \%$ had done breast self-examination. Appropriate and maximum prevention for non-communicable diseases such as breast cancer is by conducting health promotion and early detection, among others in the form of primary, secondary and tertiary prevention. The easiest and cheapest prevention is primary prevention, namely with breast self-examination because breast self-examination can be done by the individual himself without the need for health workers. Providing information with audio visual media will be more practical and flexible for the community to increase knowledge about the importance of BSE examination. Because the media is a source of information that can affect the level of knowledge. This type of research is pre experimental. The research sample was young women at MA Darul Maarif. The method to be carried out is lecture, discussion and conscious video playback. The results of research in MA Darul Maarif, most of the students had moderate knowledge of 25 students $(54 \%)$ at the pretest while the knowledge at the posttest most of the students had high knowledge of 33 students $(72 \%)$. And there is an increase in knowledge in the school before and after the intervention with audio-visual media.
\end{abstract}

Keywords: knowledge, breast examination 


\section{Pendahuluan}

Kanker payudara merupakan salah satu prevalensi kanker tertinggi di Indonesia, yaitu 50 per 100.000 penduduk. Sementara itu, kanker payudara termasuk dalam 10 penyebab kematian terbanyak pada perempuan di Indonesia dengan angka kematian 21,5 per 100.000 penduduk (Kemenkes RI, 2013).

Riset Penyakit Tidak Menular (PTM) 2016 menyatakan perilaku masyarakat dalam deteksi dini kanker payudara masih rendah. Tercatat 53,7\% masyarakat tidak pernah melakukan SADARI, sementara $46,3 \%$ pernah melakukan SADARI. ${ }^{2}$

Berdasarkan hasil pemeriksaan Clinical Breast Examination (CBE) yaitu pemeriksaan payudara yang dilakukan oleh tenaga terlatih. Kejadian kanker payudara di provinsi Jawa Tengah menunjukan bahwa dari keseluruhan WUS yang dilakukan CBE terdapat 1,42 persen WUS terdapat benjolan, ini menunjukan bahwa di provinsi Jawa Tengah masih mempunyai potensi berkembangnya kanker payudara pada wanita. ${ }^{3}$

Pencegahan yang tepat dan maksimal untuk penyakit tidak menular seperti kanker payudara adalah dengan dilakukannya promosi kesehatan dan deteksi dini antara lain berupa pencegahan primer, sekunder dan tertier. Pencegahan primer yaitu pencegahan yang dilakukan dengan menghindari keterpaparan pada faktor resiko, pola hidup sehat dan SADARI, selanjutnya adalah pencegahan sekunder yang biasanya dilakukan dengan beberapa pertimbangan tententu yaitu skrining Mammografi. Sedangkan, pencegahan tersier yaitu pencegahan yang dilakukan untuk individu yang telah positif menderita kanker payudara, tindakan yang dilakukan berupa pengobatan dan operasi. ${ }^{14}$ Berdasarkan ketiga pencegahan diatas pencegahan yang paling mudah dan murah dilakukan adalah pencegahan primer yaitu dengan SADARI karena pemeriksaan SADARI dapat dilakukan oleh individu itu sendiri tanpa perlu ke petugas kesehatan.

Upaya pemberian informasi dapat melalui pendidikan kesehatan, media audio visual, majalah, internet, dan radio. Pemberian informasi dengan media audio visual akan lebih praktis dan fleksibel bagi masyarakat dalam meningkatkan pengetahuan tentang pentingnya pemeriksaan SADARI. Sebab media tersebut merupakan sumber informasi yang dapat mempengaruhi tingkat pengetahuan. ${ }^{9}$

MA Darul Maarif merupakan sekolah SMA Swasta yang terletak di Kabupaten Semarang Provinsi Jawa Tengah. Perbandingan jumlah siswa putri lebih banyak dibandingkan dengan siswa putra. Dimana belum pernah mendapatkan penyuluhan tentang SADARI. Berdasarkan latar belakang diatas maka kami tertarik untuk mengadakan penelitian “ Peningkatan Pengetahuan Kesehatan Reproduksi Remaja Pemeriksaan Payudara Sendiri Dengan Metode Audio Visual”.

Adapun tujuan penelitian dari penelitian ini adalah mampu mengetahui peningkatan pengetahuan kesehatan reproduksi remaja pemeriksaan payudara sendiri dengan metode audio visual

\section{Metode}

Penelitian ini menggunakan desain pre eksperimental dengan pendekatan cross sectional. Penelitian dilaksanakan bulan Januari - Februari 2019 di MA Darul Ma’arif, Pringapus, Kabupaten Semarang. Sampel penelitian ini adalah remaja putri yang berjumlah 46 responden.Teknik pengumpulan data dengan menggunakan alat questioner dimana diukur pengetahuan sebelum perlakuan, lalu diberikan intervensi kemudian diukur lagi pengetahuan setelah intervensi.. Hasil Penelitian di analisis dengan menggunakan uji beda $t$ test. 


\section{Hasil Penelitian dan Pembahasan}

\section{Kegiatan Persiapan}

Adapun kegiatan persiapan dimulai dengan melakukan perijinan ke mitra yaitu MA Daarul Maarif. Perijinan dilakukan untuk mendapatkan dukungan dari mitra terhadap kegiatan yang akan dilakukan. Pada tahap ini peneliti telah mendapatkan perijinan dari mitra untuk dilakukan kegiatan penelitian peningkatan pengetahuan kesehatan reproduksi remaja pemeriksaan payudara sendiri dengan metode audio visual.

\section{Pelaksanaan}

Kegiatan penelitian di MA Darul Maarif dilakukan pada hari Jumat 1 Februari 2019 pukul 08.00 WIB. Kegiatan tersebut dilakukan di ruang kelas dengan jumlah peserta 44 orang siswi kelas X,XI,XII. Kegiatan tersebut diawali dengan melakukan pretest untuk mengukur sejauh mana pengetahuan awal dari para siswi. Kegiatan dilanjutkan dengan pemberian materi melalui audio visual yaitu dengan pemutaran video tentang sadari. Lalu dibuka sesi tanya jawab dimana ada beberapa siswi yang antusias bertanya mengenai hal yang kurang dimengerti sehubungan dengan sadari. Setelah sesi tanya jawab dirasa cukup, kegiatan ditutup untuk kemudian siswi melanjutkan kegiatan belajar mengajar.

Tabel 1. Pretest MA Darul Maarif

\begin{tabular}{|c|c|c|}
\hline Pre test & Jumlah & Prosentase \\
\hline Tinggi & 12 & 54 \\
\hline Sedang & 25 & 20 \\
\hline Rendah & 9 & 100 \\
\hline Jumlah & 46 & 26 \\
\hline
\end{tabular}

\section{Evaluasi}

Evaluasi Kegiatan penelitian di MA Darul Maarif dilakukan pada hari Jumat 8 Februari 2019 pukul 08.00 WIB. Kegiatan tersebut dilakukan di ruang kelas dengan jumlah peserta 44 orang siswi kelas X,XI,XII. Kegiatan tersebut diawali dengan pembukaan dan refresing materi. Kegiatan dilanjutkan dengan melakukan post test. Setelah posttest selesai dilakukan oleh semua siswi. kegiatan ditutup untuk kemudian siswi melanjutkan kegiatan belajar mengajar.

Tabel 2. Posttest MA Darul Maarif

\begin{tabular}{|c|c|c|}
\hline Posttest & Jumlah & Prosentase \\
\hline Tinggi & 33 & 72 \\
\hline Sedang & 13 & 0 \\
\hline Rendah & 0 & 100 \\
\hline Jumlah & 46 & 28 \\
\hline
\end{tabular}

Berdasarkan tabel 1 sampai dengan 2 dapat dilihat bahwa terdapat perbedaan pengetahuan yaitu peningkatan pengetahuan pre test dan pengetahuan post test setelah diberikan penyuluhan melalui media audio visual di kedua sekolah tersebut. 
Menurut penelitian Devi, (2012) media pendidikan kesehatan tidak hanya berfungsi sebagai pelengkap untuk membantu tenaga kesehatan memberikan informasi tetapi media memiliki fungsi yang kuat yaitu mempunyai kekuatan untuk menarik perhatian peserta. Media yang menarik akan memberikan keyakinan, sehingga perubahan kognitif, afeksi dan psikomotor dapat dipercepat.

Media video merupakan media yang mengandung unsur audio dan visual, sehingga memberi informasi yang jelas terhadap pesan yang disampaikan. Pesan yang disampaikan berupa fakta, bersifat informatif, edukatif, maupun instruksional. ${ }^{11}$ Keefektifan media audiovisual dapat dibuktikan dengan penelitian oleh (Saputra, 2011) yang menyatakan adanya peningkatan yang signifikan pada pengetahuan responden sebelum dan sesudah mendapatkan pendidikan kesehatan dengan media audiovisual. Media audiovisual juga lebih menarik perhatian, menghemat waktu dan dapat diputar berulang-ulang.

Mengingat sebagian besar umur responden tergolong dalam masa remaja yaitu masa dimana remaja mengalami perkembangan psikologis dan pola identifikasi dari kanak-kanak menjadi dewasa. Terjadi peralihan dari ketergantungan sosial-ekonomi yang penuh kepada keadaan yang relatif lebih mandiri. ${ }^{13}$ Menjelaskan tentang perubahan kejiwaan pada masa remaja. Perubahan-perubahan yang berkaitan dengan kejiwaan pada remaja adalah perkembangan intelegensia. Pada perkembangan ini menyebabkan remaja cenderung mengembangkan cara berpikir abstrak, suka memberikan kritik dan cenderung ingin mengetahui hal-hal baru, sehingga muncul perilaku ingin mencoba-coba.

Faktor-faktor yang mempengaruhi pengetahuan diantaranya pendidikan. Pendidikan berarti bimbingan yang diberikan seseorang terhadap perkembangan orang lain menuju kearah cita-cita tertentu yang menentukan manusia untuk berbuat dan mengisi kehidupan untuk mencapai keselamatan dan kebahagiaan. Pendidikan diperlukan untuk mendapat informasi misalnya hal-hal yang menunjang kesehatan sehingga dapat meningkatkan kualitas hidup. Pendidikan dapat mempengaruhi seseorang termasuk juga perilaku seseorang untuk sikap berperan serta dalam pembangunan pada umumnya makin tinggi pendidikan seseorang makin mudah menerima informasi. ${ }^{16}$

Pendidikan kesehatan adalah suatu proses yang menjembatani kesenjangan antara informasi dan tingkah laku kesehatan. Pendidikan kesehatan memotivasi seseorang untuk menerima informasi kesehatan dan berbuat sesuai dengan informasi tersebut, agar mereka menjadi lebih tahu dan lebih sehat. ${ }^{9}$ Jenjang pendidikan yang ditempuh oleh responden termasuk dalam tingkat pendidikan menengah walaupun seseorang memiliki tingkat yang tidak tinggi apabila diberikan informasi yang baik tentang kesehatan maka akan dapat meningkatkan pengetahuan seseorang khususnya tentang pemeriksaan SADARI apabila pendidikan kesehatan tentang SADARI dilakukan secara intens dapat meningkatkan pengetahuan siswi tentang SADARI

\section{Kesimpulan}

Di MA Darul Maarif, sebagian besar siswi memiliki pengetahuan sedang sejumlah 25 siswi (54\%) saat pretest sedangkan pengetahuan saat posttest sebagian besar siswi memiliki pengetahuan tinggi sejumlah 33 siswi (72\%). Dan terdapat peningkatan pengetahuan di sekolah tersebut saat sebelum intervensi dan sesudah intervensi dengan media audio visual. 


\section{Daftar Pustaka}

1. Dalimartha. S. 2011. Deteksi Dini Kanker dan Simplisia Anatikanker.Jakarta. Penebar Swadaya

2. Direktorat P2PTM Kemenkes RI. 2017. Yuk Deteksi Dini Kanker Payudara https://youtu.be/DSvW_L6ucKU; diakses pada 9 Mei 2018.

3. Dinas Kesehatan Jawa Tengah. 2016

4. Endang dan Bertani. 2009. Strategi Pencegahan Kanker Payudara. http://www.no-kita.com. Di unggah tanggal 5 Maret 2018.

5. Hikmawati, I., 2011. Promosi Kesehatan untuk Kebidanan. Yogyakarta : Nuha Medika

6. Irianto Koes. 2014. Ilmu Kesehatan Masyarakat. Bandung: Alfabet

7. Kemenkes RI. Kementerian Kesehatan Ajak Masyarakat Cegah Dan Kendalikan Kanker. Jakarta : Kemenkes RI; 2017.

8. Kementrian Kesehatan RI. 2017. Stop Kanker. Pusat Data dan Informasi Kementrian Kesehatan RI : Jakarta.

9. Notoatmodjo S. 2012. Promosi Kesehatan dan Perilaku Kesehatan. Jakarta: PT Rineka Cipta

10. Saryono \& Pramitasari, D.R.2009. Perawatan Payudara Dilengkapi dengan Deteksi Dini Terhadap Penyakit Kanker Payudara. Jogyakarta : Mitra Cendikia Press.

11. Sardiman. 2010. Interaksi dan Motivasi Belajar Mengajar. Jakarta: PT. Raja Grafindo Persada

12. Saputra, Agus.2011. Trik dan Solusi Jitu Pemrograman PHP. IKAPI: Jakarta

13. Sarwono. 2011. Psikologi Remaja.Edisi Revisi. Jakarta: Rajawali Pers.

14. Sri Handayani. 2012.Pengetahuan Remaja Putri tentang Cara Melakukan Sadari. Jurnal Nursing Studies.Vol.1.No.1.2012

15. World Health Organization. 2013. Breast Cancer Estimated Incidence, Mortality and Prevalence Worldwide in 2012. GLOBACAN 2012 (IARC).

16. Wawan \& Dewi M. 2011. Teori dan Pengukuran Pengetahuan, Sikap, dan Perilaku Manusi.Cetakan II. Yogyakarta : Nuha Medika

17. Yayasan Kanker Indonesia 2017. Penyebab Kanker Payudara. Jakarta

18. Yohana. 2011.Reproduksi Wanita. Jakarta: Garda Media

19. Yuni, Natalia Erlina \& Rika Sertiana Oktami. 2014. Panduan Lengkap Posyandu untuk Bidan dan Kader. Yogyakarta: Nuha Medika. 